LA-7080-MS Informal Report

\title{
Skull Melting of Synthetic Minerals
}

\author{
S. D. Scott \\ D. E. Hull \\ C. C. Herrick.
}


Printed in the (Inited Stales of Aineried. Avjildhle Irom Nutiurtid Technical informition Servict.

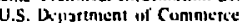

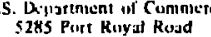

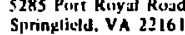

\begin{tabular}{|c|c|c|c|c|c|c|c|c|c|}
\hline inthe & 53.110 & $126 \cdot 150$ & 7.25 & 251.275 & 10.75 & $376-4011$ & 13.010 & $501-525$ & 15.25 \\
\hline & & $151-175$ & 8.11 & $276.3(11)$ & 11.00 & $401-425$ & 13.25 & $\$ 26-550$ & 15.50 \\
\hline $1126-050)$ & 4.50 & 176.2011 & 9.00 & $301-325$ & 11.75 & $426-450$ & 14.00 & $551-575$ & 16.25 \\
\hline IJS1-1175 & 5.25 & 201.225 & 9.25 & 326.350 & 12.110 & $451-475$ & 14.50 & $576-600$ & ib.sn \\
\hline $676-100$ & 6.00 & 226.250 & 9.50 & $351-375$ & 12.50 & $476-500$ & $15.111 \mathrm{t}$ & 601.up & --1 \\
\hline
\end{tabular}

1. Add \$2s0 fot cach additional 100-pase increment from 601 p1ges up.

This repurt was prepared at an wccitunt of wark spunsared the United Stutes Government. Neither the United Swtes nor the United Stentes Department of Einerky, nur ant ut thesr imploveres nor any nf their contractiss, subcuntractars, or their umployees, mukes yny werrisnty, express im implied, or dssumes uny leat liability or responsubility for the acruraey. rumpirtenext, of uw(u)ness of any infurmation, uppuralus.

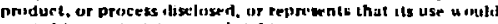
nem infrinke prisutcly owned naht. 
CONTENTS

I. INTRODUCTION . . . . . . . . . . . . 1

II. THE SKULL MELTING PROCESS . . . . . . 2

III. POWER INPUT TO CHARGE . . . . . . . . 5

IV. CAGE GEOMETRY . . . . . . . . . . 8

V. POWER SUPPLY AND COIL GEOMETRY . . . . . 15

VI. OPERATING HINTS . . . . . . . . . . . 16

VII. EXPERIMENTAL RESULTS . . . . . . . . . 17

VIII. CONCLUSIONS AND RECOMMENDATIONS . . . . 18

REFERENCES ............... . 18

APPENDIX ................ . Al

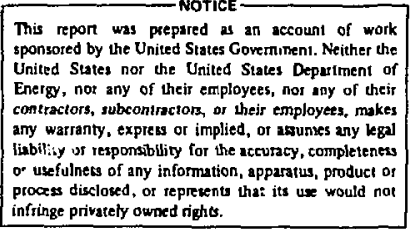


SKULL MELTING OF SYNTHETIC MINERALS

by

S. D. Scott, D. E. H」ll, and C. C. Herrick

\begin{abstract}
ABSTRACI
Direct high-frequency induction melting of dielictric materials in a water-cooled cage has been developed in the synthetic minerals program at Los Alamos Sclentiflc laboratory. Molten material is contained in a skuii, $1 . e$. , sintered she11, of its own composition so the traditional problems associated with refractory melt contamination are essentially eliminated. Preliminary analyses of power input, cage design, and coll geometry are discussed. Initial experimental results on the preparation of polycrystalline ingots, single crystals, and glasses are presented along with possible applications of this technique.
\end{abstract}

\title{
I. INTRODUCTION
}

In 1974, Russian scientists at the Lebedev Physical Institute ${ }^{1}$ reported the development of a new process for melting kilogram quantities of refractory materials without either crucible or electrode contamination. Termed "skull melting" because of the sintered shell, or skull, of primary powder that encases the melt, the technique uses direct high-frequency induction heating of dielectric materials contained in a water-cooled cage.

skull melting has been used in the fabrication of refractory single crystals, refractory glasses, and melt-cast ceramics with weights up to 25 kilograms. Further development of this technique can make a substantial contribution to:

1. studies of properties of melts at high temperature, chemical reactions in melts, solid-melt-gas equilibria, solidification of high-temperature melts and modeling of geothermal processes,

2. stable, corrosion-resistant, high-temperature materials for electrode lining for use in magneto-inydrodynamic generator channels, controlled theraionuclear fusion reactor walls and sheathing in continuously combusting automotive engines,

3. electrical heating elements which work at $2000^{\circ} \mathrm{C}$, 
4. refractory materials for use in pyrometallurgical processes,

5. preparation of solid electrolytes and semiconductors,

6. synthetic mineral single crystals for elastic constant measurements, fracture mechanics studies, and synthetic jewels,

7. encapsulating high-level radioactive waste products as stable, nonleachable ingots.

The application of skull melting to the production of a wide variety of new materials, with their corresponding large variation in electrical and thermal properties, will require a thorough understanding of the physics in.olved. Work completed at the Air Force Cambridge Research Laboratory by Wenkus and coworkers $^{2}$ established basic design criteria for skull melting apparatus, including simple geometrics for the water-cooled cage and power requirements for the RF (radio frequency) source. As part of the synthetic minerals program at LASL skull melting has been used in the preparation of forsterite, magnesia, hafnia, stabilized zirconia and thoria (Fig. 1). In support of these efforts a pre1iminary theoretical and experimental analysis of skull melting has been

initiated. Attention has centered on:

1. the perturbation in applied magnetic fields produced by the water-cooled cage,

2. the functional dependence of power absorption by the melt and cage on conductivity and RF frequency,

3. the cage effect on coil inductance and its implications for new apparatus designs to produce large magnetic fields,

4. melt stability as a function of irrequency,

5. operating procedures for initial melting and cooling procedures for single-crystal production.

This preliminary report sumarizes results obtained during the spring and summer of 1977.

\section{THE SKULL MELTING PROCESS}

Typical skull melting configurations are illustrated in Figs. 2 and 3 . Figure 2 depicts a concentrator-type cage melter--a cylindrical water-cooled unit with a thick sleeve near the center and a single slot to prevent eddy current closure. A water-cooled copper pedestal is positioned at the bottom to support a powdered charge. The dimensions shown do not correspond to any existing cage, but serve as a useful starting point for calculations of typical power losses and flux geometrics. Figure 3 shows a fingers-type cage melter, formed from nine water-cooled copper hairpins and a solid water-cooled bottom. The shown dimensions are those of the experimentally employed cage. Both cages are isolated from the three-to five-turn induction coil by a quartz sleeve.

Initially, the cage is filled with isostatically pressed oxide powder, topped by a small (approx. 1-to 2-in.-diam) graphite ring or a few grams of metal chips to serve as an initiator. Additions of loose powder are poured over the initiator (graphite ring or metal chips) to a depth of about 0.5 inch. The RF power (3-4 MH a) is slowly increased until a plate voltage of $5-6 \mathrm{kV}$ is ovtained. Within a few minutes, the initiator becomes incandescent and sufficient erergy reaches the adjacent powder to cause melting. An increase in the RF-coil current indicates more efficient coupling occurred with the increase in electrical conductivity accompanying the phase transition from solid to molten oxide. The small seed melt absorbs sufficient power to melt adjacent powder, and within less than an hour, a large, stable melt can be obtained. 


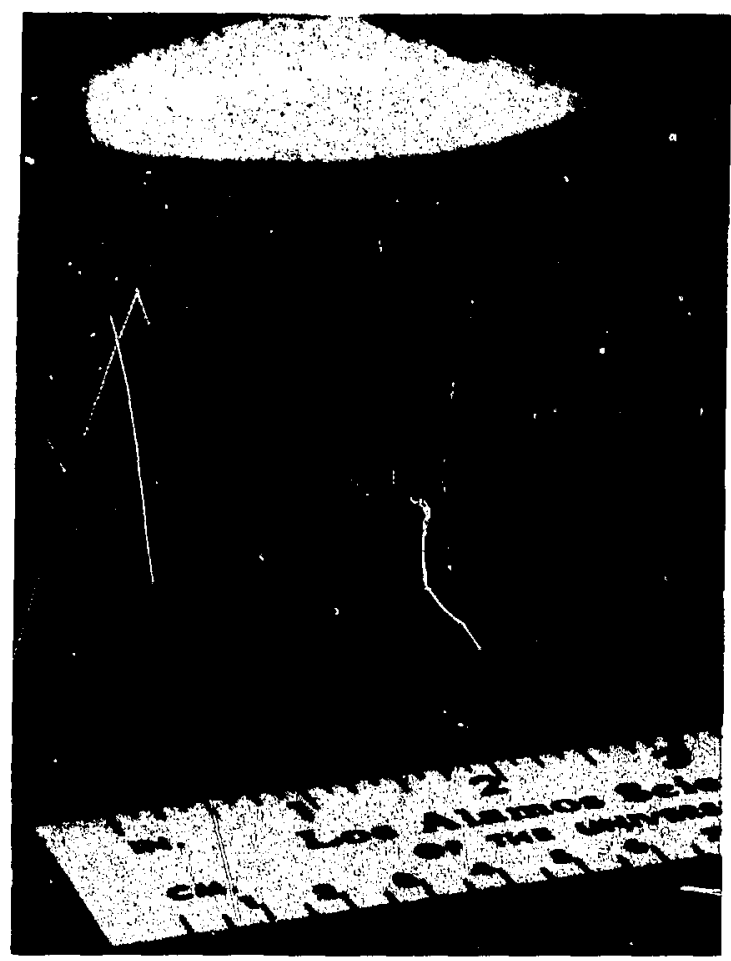

FORSTERITE

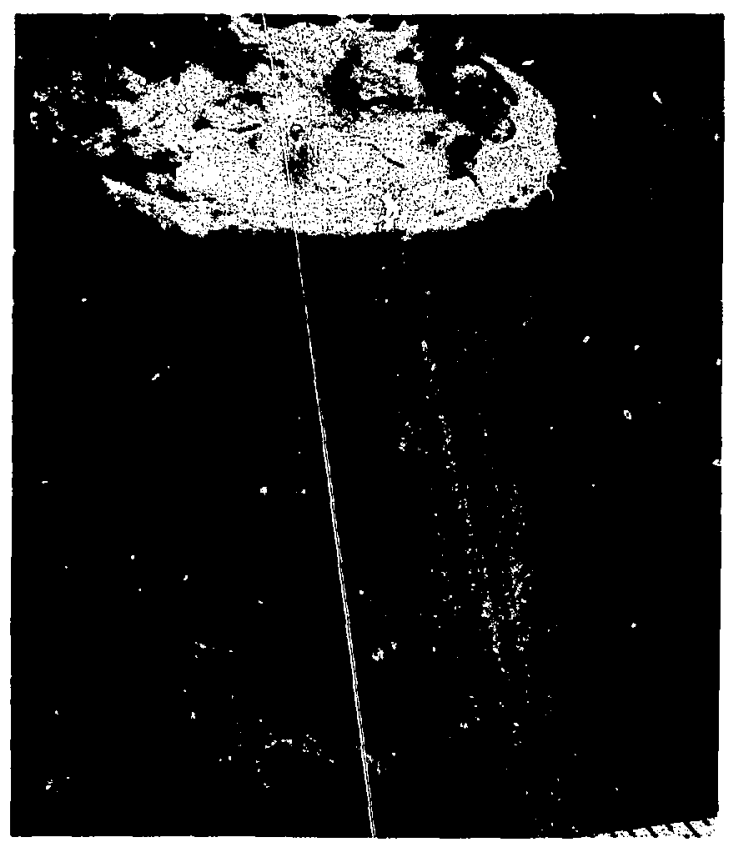

HAFNIA

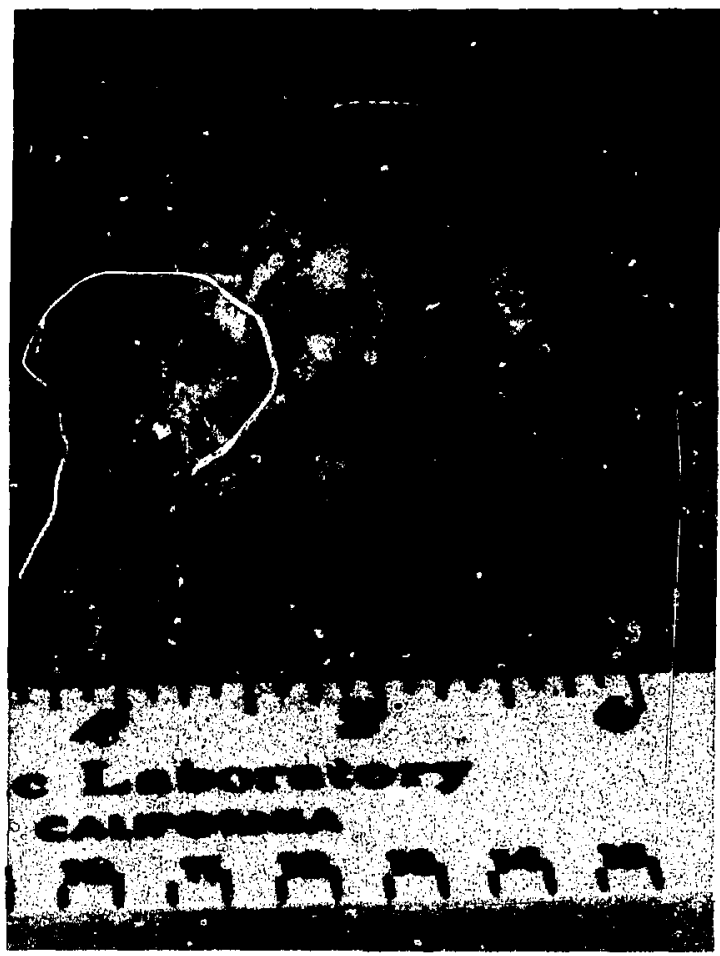

FUSED MgO

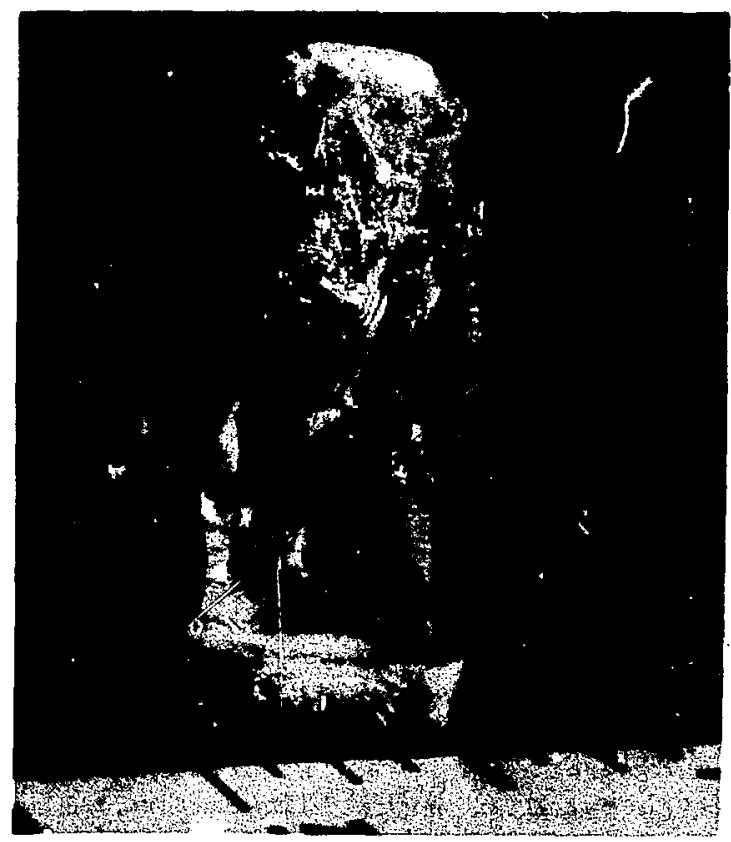

\section{ZIRCONIA}

Fig. 1. Experimental results with skull melting. 


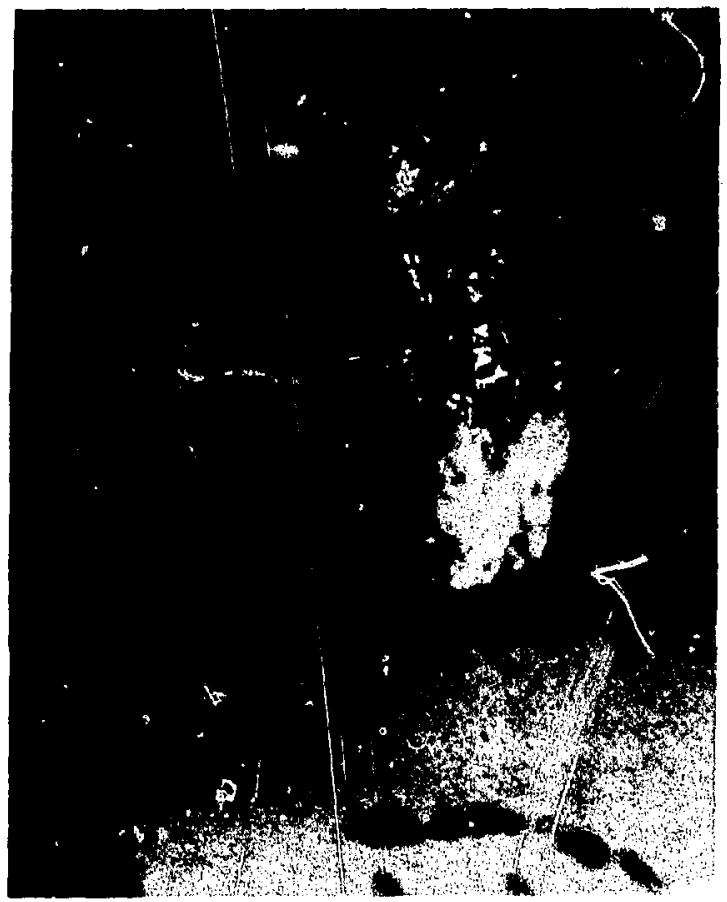

THORIA SINGLE CRYSTALS

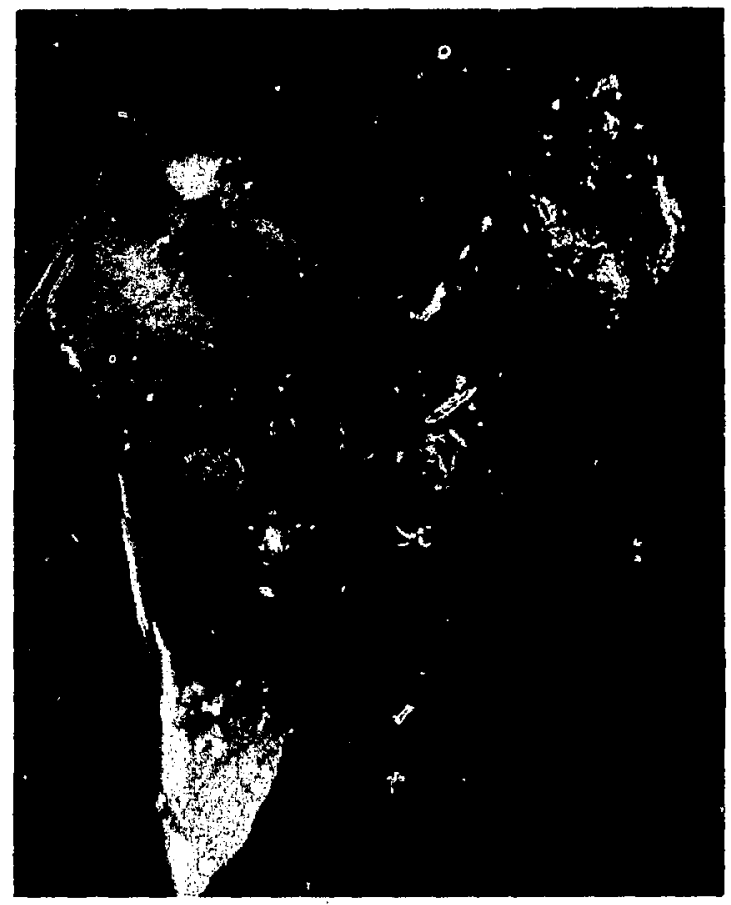

SINGLE CRYSTAL $\mathrm{ThO}_{2}$

Fig. 1. (Cont)

At the upper oxide surface, molten oxide cannot be sustained because enormous radiation losses occur $\left(3 \mathrm{kw} / \mathrm{in}^{2}\right.$ at $\left.3000^{\circ} \mathrm{C}\right)$. Sintering takes place in this region yielding a hard shell that must be repeatedly punctured if feed powder is to be added.

The design and operation of a skull melting apparatus is restricted by several factors, that complicate the fusion of certain very refractory materials.

1. Arcing between cage fingers or to the RF coll. (The high voltages that exist between various components of the apparatus, coupled with the dusty environment, make the cage melter and coil susceptible to azcing, which reduces the power available to the melt and corrodes the wall material.)

2. Available power. (Very refractory materials such as thorla require a high-power input per unit volume to sustain the melt against thermal osses.)

3. Cage cooling capacity. (The cooling capacity of the cage is limited by the outlet water temperature. On occasion too much heat is conducted into the water. lines, bolling ensues, cooling capacity drops, and the resulting pressure disrupts the o-ring seals, thus creating a hazardous situation.)

4. Outgassing. (Densification and melting are accompanied by continuous release of gas.that is trapped beneath the hard skull. If the skull is not porous or perlodically punctured, gas pressure will force molten oxide between the Ingers, occasionally breaking the quartz, or the system will erupt, spewing molten material in all directions.)

5. Skin depth instability. (Early attempts to melt thorla (m.p. $=3400^{\circ} \mathrm{C}$ ) consistently failed after the seed melt had been established. The problem is thought to be assoclared with the skin depth (the distance over which the applied fleld attenuates a factor 1/e) of the molten charge, which at $3.6 \mathrm{MHz}$ may be 


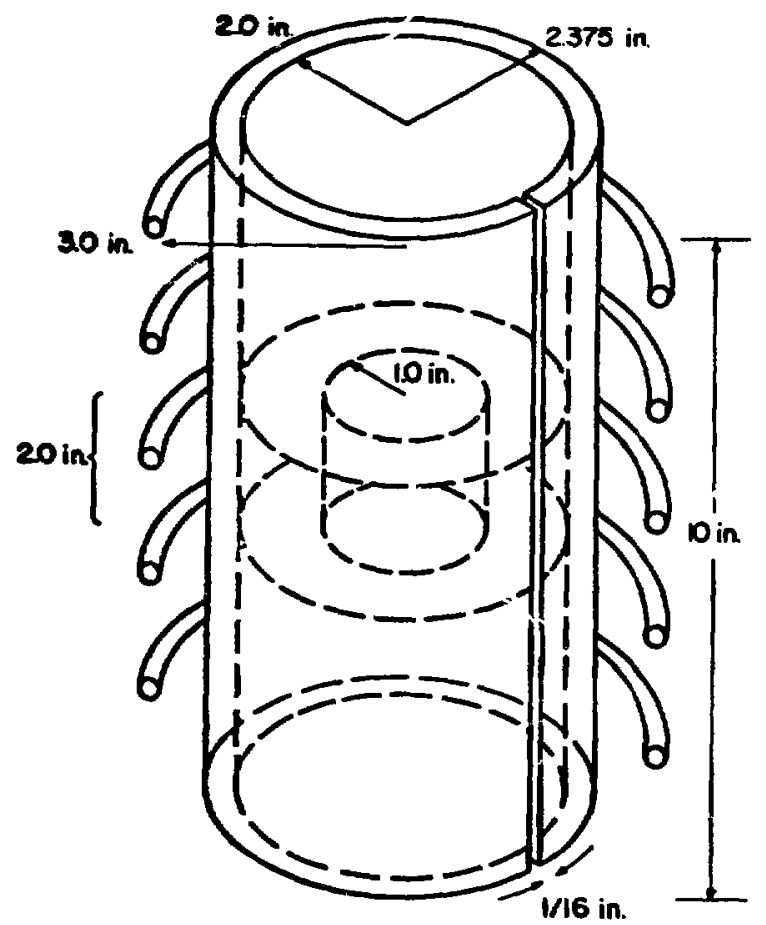

Fig. 2. Concentrator-type cage melter. All surfaces are water cooled. Five-turn coil carries $100 \mathrm{~A}$. i.d. $=3-1 / 16$ in.

$0 . d=4-3 / 8$ in $1 / 16$ TO

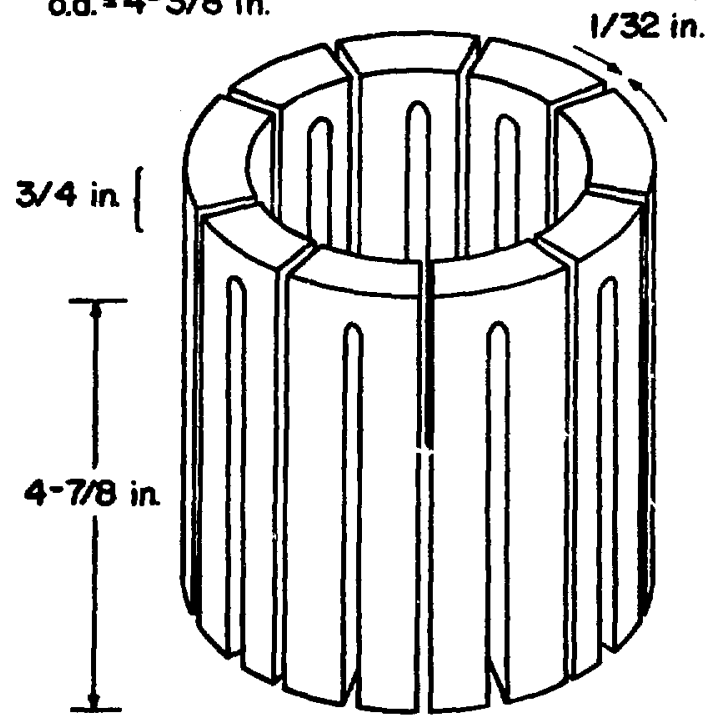

Fig. 3. Fingers-type cage melter. A11 copper surfaces, including solid bottom, are water cooled.

much smaller than the melt itself. This produces a melt geometry that is unstable when the skull is broken for feed powder additions.)

The experimenter has control over several groups of parameters which affect the melting performance, and which may be altered to alleviate operational problems. These are in coil geometry (number of turns, radius, and length), cage geometry, and RF-power generator capabilities. The coil geometry is easiest anc? cheapest to change. Cage modifications are more difficult and expensive to change, i.e., major design changes typically consume sixty hours of machining time. Some operating characteristics of the power supply, such as frequency, may be varied over a limited range through simple tuning circuits, but other characteristics such as an increase in maximum power require heavy investment. Therefore it is useful to understand the parametric behavior of a skull melting unit so its unique capabilities can be fully exploited at minimum cost and effort.

\section{POWER INPUT TO CHARGE}

An alternating magnetic field inside a material produces an electric field, which in turn induces electric currents in proportion to the electrical conductivity. These currents supply heat energy to the material through normal ohmic losses. The electrical conductivity of most solid refractory oxides is so low $\left(10^{-12}-10^{-4}\right.$ mho/m) that direct RF absorptton is negligible, only a small fraction of a watt per $\mathrm{cm}^{3}$ (cubic centimeter) for applied magnetic fields of several 
thousand amperes/meter. Upon melting, the electrical conductivity increases dramatically (Fig. 4) and the oxides become effective RF power absorbers. The absorbec power sustains the melt against thermal losses by conduction and radiation, and melts additional powder adjacent to the melt. Thus it is sufficient to Initially melt only a small portion of the charge for the process to ccntinue by high-frequency energy absorption.

Raising an Insulating powder from room temperature to its melting point can be accomplished by external heating sources such as electric arc, plasma jet, laser or radlation furnace, or internally by RF coupling to conducting metal chips or graphite. In principle, the external heating sources are preferable, because they cannot contaminate the melt. However, they are more expensive and, except in the case of a laser, difficult to install near a multikilowatt power source. Keem ${ }^{3}$ (Purdue University) has initiated melts of thoria in a few minutes using a 300-watt $\mathrm{CO}_{2}$ laser. At LASL oxide charges have been seeded with graphite rings or several grams of metal chips. The latter proved superior, yielding melts more rellably and with less contamination than graphite rings. The metal used is a component of the oxide. Inftiation with metal chips is not always feasible, i.e., cerlum oxides rapidly in air and is hazardous to machine, so without an external energy source one must at times be content with a graphite ring, followed by a long heating period to vaporize out the graphite impurity.

Survival of the initial melt depends on its initial geometry and volume, power input, thermal conductivity of the solid phase, heat transfer coefficient of the liquid-solid interface, and the solid and melt temperatures. Energy losses through conduction are approximately proportional to the surface area of the melt. Wenckus ${ }^{2}$ showed that the molten region tends to assume the shape of a flattened body of revolution, with the major source of heat in a ring near the equatorial plane close to the surface of the body. The heat source is particularly concentrated on the melt surface if the skin depth of applied radiation, 1.e., the distance over which the applied fleld attenuates a factor $1 / e$, is smaller than the melt dimensions. The skin depth

$$
\delta=(2 / \mu \omega \sigma)^{1 / 2}
$$

of refractory oxides at $3 \mathrm{MHz}$ varies from 10 centimeters to a fraction of a centimeter, depending on the conductivity $\sigma$, the frequency $\omega$, and the permeability $\mu$. Whatever the skin depth, the center of a melt absorbs relatively little RF power per unit volume, and is heated primarily by conduction from the outer regions.

For mathematical convenience Wenkus ${ }^{2}$ approximated the shape of a molten region as an oblate spheroid of semimajor axes a and $c$ :

$$
\frac{r^{2}}{a^{2}}+\frac{z^{2}}{c^{2}}=1
$$

where $r$ and $Z$ are the horizontal and vertical coordinates. For $\delta \gg c$, the uniform magnetic field $H_{0}$, produced by the coll, penetrates the melt with little distortion, and the absorbed power is

$$
\mathrm{W}_{1}=\frac{\pi \sigma \mu_{0}^{2} \omega^{2} \mathrm{a}^{4} \mathrm{cH}_{\mathrm{o}}^{2}}{15}=\frac{2 \pi}{15} \frac{\mu_{\mathrm{o}} \omega \mathrm{a}^{4} \mathrm{cH}_{0}^{2}}{\delta^{2}} .
$$




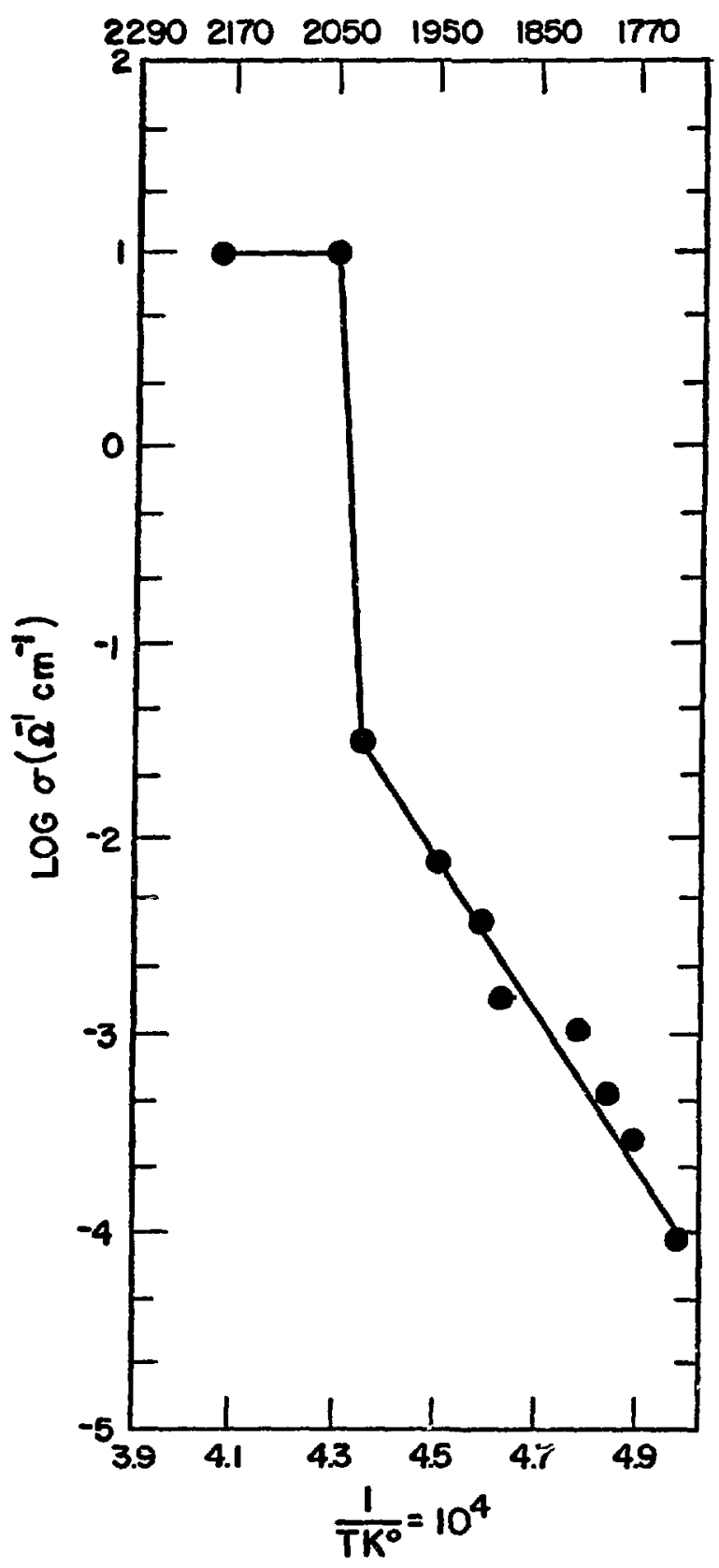

Fig. 4. Temperature dependence of electrical conductivity of $\mathrm{Al}_{2} \mathrm{O}_{3}$
As a numerical example we take the following values:

$$
\begin{aligned}
& \sigma=1000 \text { mho/meter } \\
& a=.0222 \text { meter } \\
& c=a / 4 \\
& H_{0}=4175 \text { ampere-turns/meter } \\
& \omega=2 \pi\left(3 \times 10^{6}\right) \mathrm{Hz} \\
& j=0.0092 \text { meter } \approx 2 \mathrm{C} \\
& \mu_{0}=4 \pi \cdot 10^{-7}
\end{aligned}
$$

then $W_{1}=2755$ watts. The values of $H_{0}$ and $\omega$ are those of the concentratortype cage melter with "a" chosen for a 7/8-in. melt radius; the conductivity is a handbook value for molten zirconia. It is important to note that, for $\delta>>c$, the power loss

1. increases linearly with the conductivity $\sigma$,

2. depends strongly on the melt dimensions $\mathrm{a}^{4} \mathrm{c}$, and

$$
\text { 3. is proportional to } \omega^{2} \mathrm{H}_{0}^{2} \text {. }
$$

The strong dependence on melt dimensions determines the smallest melt that can be sustaitied for a given magnetic field. Thus when initiating a melt, it is advantageous to position the metal chips in a $r$ ing of maximum radius (perpendicular to the magnetic field) so as to create a melt with a large major semiaxis. The $\omega^{2} \mathrm{H}_{\mathrm{O}}^{2}$ factor in Eq. (1) would imply that the power input increases with the square of the frequency, but for a constant voltage drop across the RF coil, the axial magnetic field $H$ varies approximately as $1 / \omega$, hence over a wile range of frequencies the power input is independent of frequency. At very low frequencies $H$ falls faster than $1 / \omega$ and the power input is diminished.

At high frequencies where $\delta \ll c$, the magnetic fleld is excluded from the interior of the melt, and the power absorbed by the melt surface is 


$$
W_{2}=\frac{H_{0}^{2} a^{2}}{20 \delta} F(c / a)=\frac{H_{0}^{2} a^{2}}{2}\left(\frac{\omega \mu_{0}}{2 \sigma}\right) F(c / a),
$$

where $F(c / a)$ is a geometry function which is essentially constant over the Interval $\mathrm{c} / \mathrm{a}=0.1$ to 1.0 (sec Table $\mathrm{I}$ ). Assuming the same materlal properties and dimensions as in the $\delta \gg c$ example, the skin depth $\delta$ becomes equal to $c$ at a frequency of $10.13 \mathrm{MHz}$ : For a constant potential drop across the $\mathrm{RF}$ coil, $\mathrm{H}$ is reduced to 1236 ampere/meter at $10,13 \mathrm{MHz}$ and the power input is $\mathrm{w}_{2}=506$ watts.

If the coil voltage at $10.13 \mathrm{MHz}$ were increased to produce the same magnetic field as at $3 \mathrm{MHz}$ the power input necessary would be $\mathrm{W}_{2}=5769$ watts.

Equations (1) and (2) show that as $\sigma$ varies from sma11 to large values, due to temperature varlations, the power absorbed passes through a maximum which, for the parameters chosen, 1les between 2800 and 5800 watts.

Several experiments with isostatically pressed thoria powder, using a threeturn coil at $3.4 \mathrm{MHz}$ and $20 \mathrm{kw}$ applied power, terminated abruptly when the melt cooled and solidifled after addition of feed powder. Examination of the charge revealed a hollow, glass-lined oblate spherold, with a thick base containing a few single crystals and thorla glass, encased in a thick skull of sintered thoria. This geometry is consistent with the assumption of a small skin depth sur molten thoria, which would produce a thin molten shell with the interior powder heated only by conduction and radiation. The result would be a growth of crystals along the vertical walls and a settling of the interior powder on the bottom of the void. Furthermore; should the thin layer of melt be broken by a charge of cold feed material or by puncturing the skull, the system would become unstable, and the complete cooling observed becomes predictable.

This hypothesis was tested by malting thoria at $2.6 \mathrm{MHz}$. Although the calculated increase in sing depth, attributable to the frequency, is a mere $20 \%$, a stable 3500-gram melt was obtained and held for over five hours.

This experiment suggests that for optimum performance and stable operation, the akin depth should be approximately equal to the melt radius. Under this condition, the power input to the melt for a constant voltage drop is nearly maximized. Because the experimenter has no control over the melt's intrinsic electrical and magnetic properties, the skin depth parameter can only be influr enced through the RF frequency. Even among a restricted class of materials such as refractory oxides, there is an enormous varlation (orders of magnitude) in conductivity; hence an RF generator, or a set of them, with broad frequency capability is necessary for experimental purposes.

\section{CAGE GEOMETRY}

A multiturn coil operated at a frequency of several megahertz produces a strong magnetic field in the interior that is approximately constant throughout the volume, and directed along the axis of the coil. Since the alternating magnetic field is the power source for a melt, it is of interest to determine how the cage structure alters the applied field. The conclusion is that, except near the solid bottom of a cage, the magnetic field geometry is entirely unaffected by the presence of the cage, but the magnitude of the fleld may be substantially increased through a reduction in coil inductance. Arcing problems between components of the cage can be remedied in the fingers-type cage by using a large number of hairpin fingers. For the single-slotted concentrator-type cage the arcing problem is essentlally insoluble and places a severe constraint on the magnitude of magnetic field that can be attained. 
TABLE I

GEOMETRICAI FACTOR $\mathrm{F}(\mathrm{c} / \mathrm{a})$

\begin{tabular}{lrr}
\multicolumn{1}{c}{$c / a$} & & $F(c / a)$ \\
0.0001 & & 24.020 \\
0.001 & & 18.101 \\
0.01 & & 12.534 \\
0.1 & & 8.190 \\
0.2 & 7.510 \\
0.25 & 7.465 \\
0.4 & 7.564 \\
0.6 & 8.121 \\
0.8 & 8.744 \\
1.0 & & 9.425
\end{tabular}

A. F1ux Geometry

When electromagnetic fields with frequencies in the megahertz range impinge upon conducting surfaces, they induce surface currents which cancel the Incident field inside the material. Alternating electric and magnetic fie.lds are thereby excluded from the conductor except in a thin layer (specified by the skin depth) near the surface. In MKS units the surface current $\mathrm{K}$ is given by

$$
\mathrm{K}=\underset{\sim}{\mathfrak{n}} \mathbf{x} \underset{\sim}{\mathrm{H}}
$$

where $H$ is the magnetic field at the surfacẽ and $n$ is a unit normal to the surface. $\underset{\sim}{H}$ satisfies.

$$
\underset{\sim}{\mathrm{H}} \cdot \underset{\sim}{\mathrm{n}}=0
$$

at all. conducting surfaces, $1 . e$. , it has no component normal to the surface. In both cage designs, the current induced in the outside walls is equal in magnitude to the applied $\underset{\sim}{\mathrm{H}}$ field, and is directed in the $\theta$ direction. These currents loop around the inside of the cage structure, producing a magnetic field nearly identical to the field outside. It is tempting to draw an analogy between the magnetic flux lines in a concentrator-type cage and the velocity field in a constricted water line, but the analogy is false. The slot in the concentrator forces continuity between currents on the inner and outer surfaces, hence the fields inside and out are nearly identical. Viewed differently, the slot allows magnetic field lines to slip out of the cage as they approach the constricting sleeve.

\section{B. Computer Program}

The magnetic field $\underset{\sim}{\mathrm{H}}$ satisfies the wave equation

$$
\left(\nabla^{2}+\mathrm{k}^{2}\right) \underset{\sim}{\mathrm{H}}=0
$$

where $K=\omega / c$ everywhere in space. Because the normal component of $\underset{\sim}{H}$ must vanish at all surfaces of the cage, $\nabla$ is of the order $1 / r_{0}$ where $r_{0}$ is some characteristlc dimension of the cage, typically 0.1 meter. At $3 \mathrm{MHz}^{\circ}, \mathrm{K}=2 \pi . / 100$ meter, hence $\nabla^{2} \approx 100 / \mathrm{m}^{2}$ and $\mathrm{K}^{2} \approx 0.004 / \mathrm{m}^{2}$. Evidently $\nabla^{2}>\mathrm{K}^{2}$, so to a good approximation $\nabla_{\sim}^{2} \underset{\sim}{\mathrm{H}}=0$ inside the cage.* This approximation is equivalent to neglecting

*Note this approximation is not valid for the case of a hollow cylinder with no slot. For such a geometry the magnetic field is attenuated inside, hence the gradients in the interior are much less than the estimate $H / r_{0}$ as given. 
the time rate of change of magnetic field in Maxwell's equation

$$
\nabla \times \underset{\sim}{\mathrm{E}}=-\underset{\sim}{\dot{B}} \text {. }
$$

On conducting surfaces $\dot{B}$ is not negligible, and this is reflected in the boundary conditions $\mathrm{n} \cdot \underset{\sim}{\mathrm{H}}=0, \underset{\sim}{\mathrm{n} \times \mathrm{H}}=\mathrm{\sim}$.

To facilitate computer solution of the system,

$$
\begin{aligned}
& \nabla^{2} \underset{\sim}{\mathrm{H}}=0 \\
& \underset{\sim}{\mathrm{n}}=0
\end{aligned}
$$

at a11 conducting surfaces, we write $H=-\nabla \phi$. Then

$$
\begin{aligned}
& \nabla^{2}{ }_{\phi}=0 \\
& \partial \phi / \partial n=0 \text { at all conducting surfaces. }
\end{aligned}
$$

A computer code written by John Hayes ${ }^{4}$ for the solution of $\nabla^{2} \phi=0$ in axisymmetric systems with Neumann or Dirichlet boundary conditions was modified for use in solving the system (4). While the code satisfied all the Maxwell equations to a good approximation, it does not impose the constraint of continuity of current on the inner and outer surfaces. Furthermore, being an axisymmetric code It cannot allow flux lines to pass through a slot along the length of the cage. Thus, once the flux lines enter the top of the cage, the code forces them to remain Inside the cage, resulting in an artificial magnification of magnetic field intensity within the constricting sleeve of the concentrator. Nonetheless, the program provides a fairly accurate description of the field geometry, and the numerical results are useful for comparison with analytical expressions.

Computer-generated plots of the magnetic flux 1ines for the sample concentrator cage and coil configuration are shown in Figs. 5 and 6 . Note especially the dead space near the inner sleeve where the magnetic field intensity is

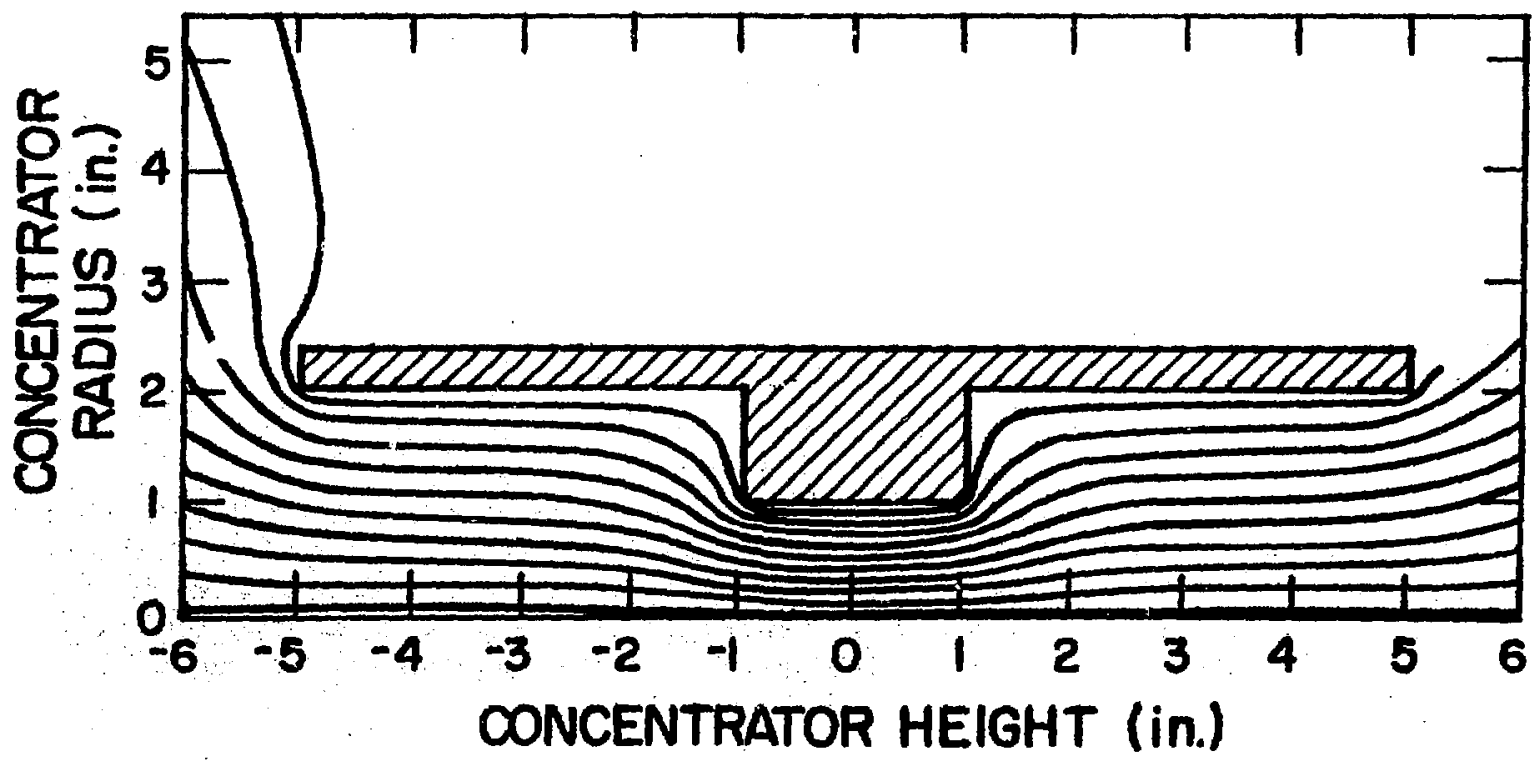

Fig. 5. Magnetic flux lines for sample concentrator colls at $-2,-1,0,1$, and 2 in. 


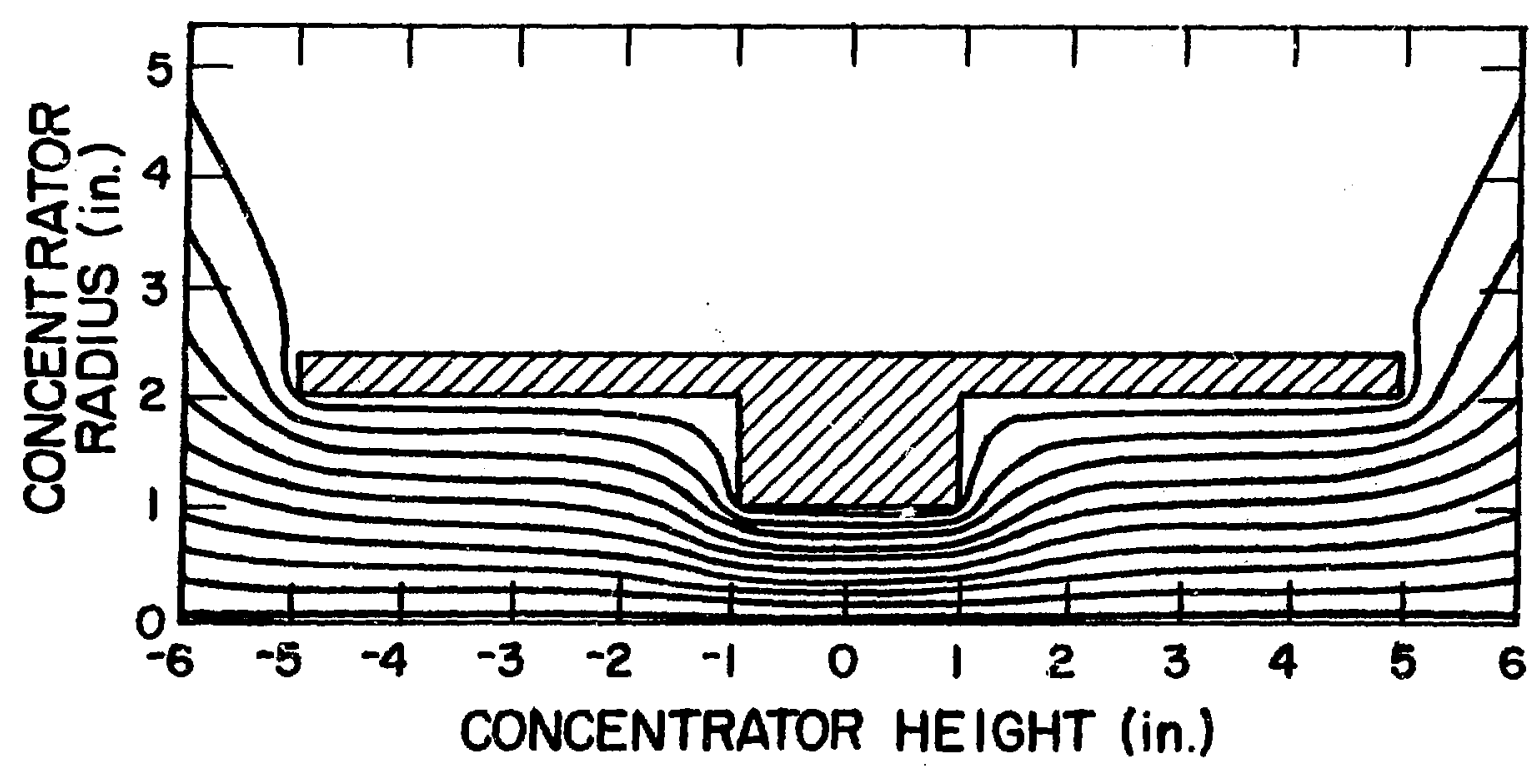

FIg. 6. Magnetic field lines for sample concentrator coils at $0,1,2,3$, and 4 in.

very small -- stable melts cannot be maintained in these regions because insufficlent power is avallable. As expected, the assumed cage axisymmetry prevents any flux lines from leaking out the sides of the cage, and results in an artificially high calculated magnetic field intensity within the constricting sleeve (see the Appendix).

\section{Fields Near Cage Bottom}

At the solid bottom of a cage melter the Z-component of the magnetic field must vanish. Along all vertical walls $B_{z}$ is approximately constant and equal to the B-field outside the cage. The current distribution in the hairpin fingers, viewed from the top, is shown in Fig. 7.

The effective current distribution may be approximated by a cylindrical current sheet. In the interior region the governing equation for $B$ is,

$$
\nabla^{2} \underset{\sim}{B}=0
$$

and

$$
\nabla^{2} B_{Z}=0
$$

Very far from the bottom of the finger, $B=\mu_{0} I$ where $I$ is the current per unit length in the walls. Let $B_{2}=\mu_{0} I$ and, say, $Q^{I}=20 \mathrm{r}_{0}$ be a boundary condition. (The choice of boundary condition is not important when one is far from the region of. Interest.) The the system to be solved is 


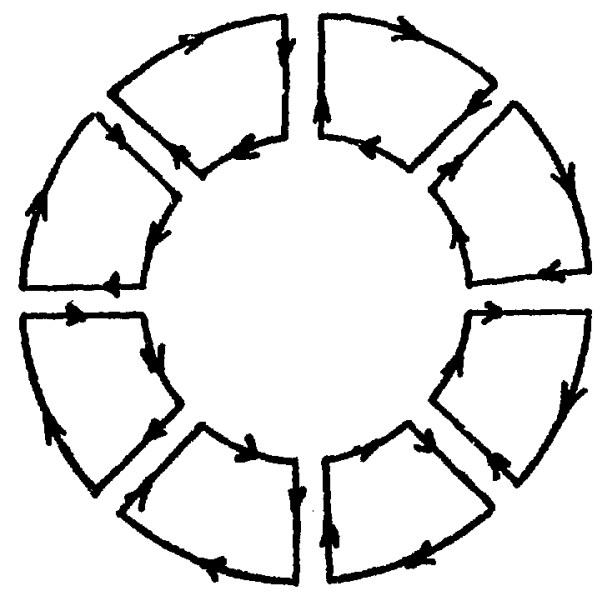

Fig. 7. Induced currents in cage fingers (top view).

$$
\nabla^{2} B_{Z}=0
$$

with $B_{z}=\mu_{0} I$ at $r=r_{0}$

$$
B_{z}=\mu_{0} I \text { at } z=20 r_{0}
$$$$
B_{z}=0 \text { at } Z=0
$$

The solution is

$$
\begin{aligned}
& B_{z}= \frac{4 \mu_{0} I}{\pi}\left(\sum_{n=0}^{\infty} \frac{\sin \left((2 n+1) \pi t / 20 I_{0}\right.}{(2 n+1) I_{0}} .\right. \\
&+2 \mu_{0} I \sum_{n=1}^{\infty} \frac{((2 n+1) \pi s / 20}{\pi / 20)} \frac{J_{0}\left(x_{n} s\right) \sinh \left(x_{n} t\right)}{J_{1}\left(x_{n}\right) \sinh \left(20 x_{n}\right)} x_{n}
\end{aligned}
$$

where

$$
\begin{aligned}
& \mathrm{s}=\mathrm{r} / \mathrm{r}_{0} \\
& \mathrm{t}=\mathrm{Z} / \mathrm{r}_{0} \\
& \mathrm{I}_{0}=\text { First modified Bessel function } \\
& \mathrm{J}_{0}=\text { First Bessel function } \\
& \mathrm{J}_{1}=\text { Second Bessel function } \\
& \mathrm{X}_{\mathrm{n}}=\mathrm{n} \text { th root of } \mathrm{J}_{0}
\end{aligned}
$$

of $\mathrm{B}_{\mathrm{Z}}^{2} /\left(\mathrm{B}_{2}^{2}\right)$ power available to a melt varies as $\mathrm{B}_{\mathrm{Z}}^{2}$. In Fig. 8 equipotential 1ines seen that $80 \%$ of maximum avallable power is attained at distances greater than a single radius from the bottom.

\section{Arcing Between Fingers on Slotted Surfaces}

The changing magnetic field inside the cage induces electric fields, which are sometimes strong enough to cause arcing between components of the cage. Assuming a uniform, axial magnetic fleld $\mathrm{H}$ inside the cage, the potential difference induced around a circular loop C in Fig. 9 is

$$
|\Delta v|=\int_{C} \underset{\sim}{\mathrm{E}} \cdot \underset{\sim}{\mathrm{d}}=\int_{\sim}^{\mathrm{B}} \cdot \underset{\sim}{\mathrm{da}}=\text { wuHI } \pi \mathrm{r}_{\mathrm{O}}^{2} .
$$




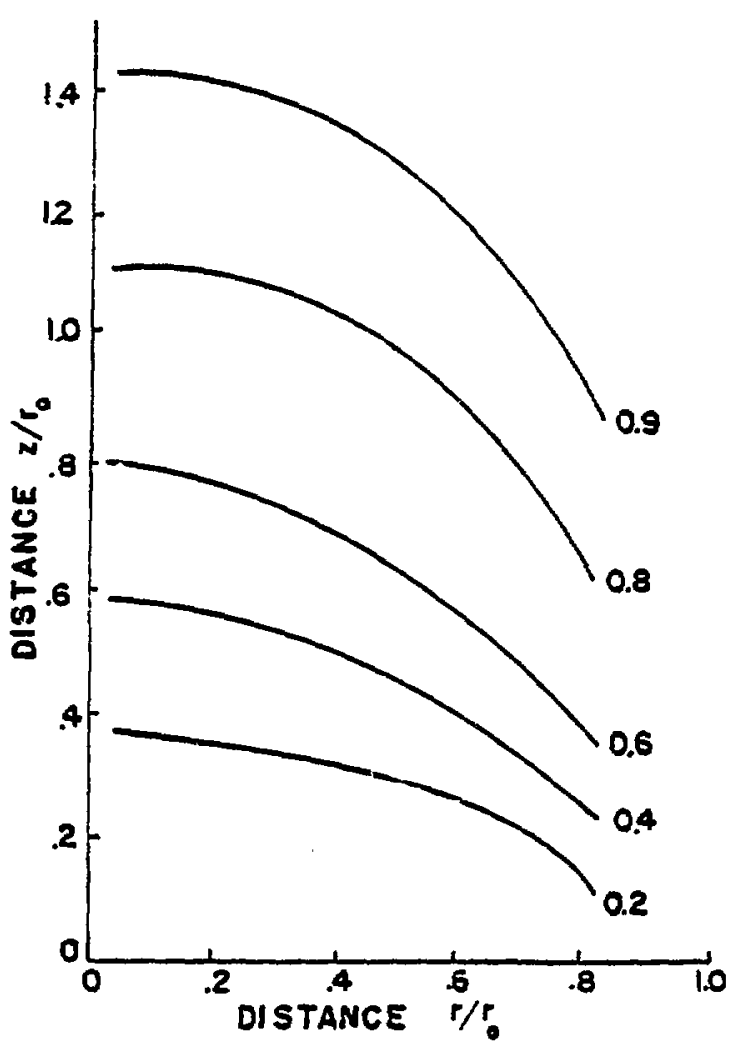

Fig. 8. Fraction of maximum available rf power near bottom of cage melter (equipotential lines of $\left.B_{z}^{2}\right)$.

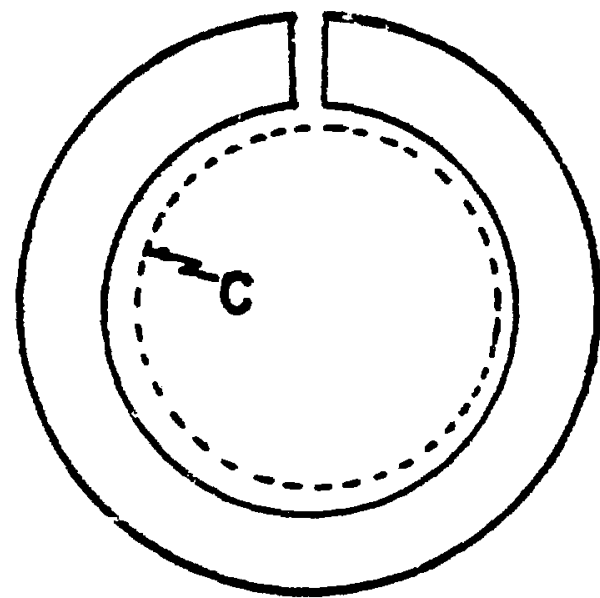

Fig. 9. Cage Concentrator (Top View).

The surface current $K$ produces a potential drop around the cage wall that is a factor $r_{0} / \delta$ smaller than $|\Delta V|$, so the entire potentlal difference $|\Delta V|$ occurs between the two slotted surfaces. In a fingers arrangement, the potential difference is $\Delta V / N_{f}$, where $\mathrm{N}_{f}$ is the number of fingers, $\mathrm{F}_{i . e .,}$

$$
\Delta \mathrm{V}=\omega \mu \mathrm{H} \pi \mathrm{r}_{\mathrm{O}}^{2} / \mathrm{N}_{\mathrm{f}} \text {. }
$$

For a 3 -turn coil of 3-in. radius and 4-in. length, carrying an average current of 100 amperes, the potential difference across a 4-in.-diam cage is

$$
\Delta \mathrm{V}=802 \mathrm{volts} / \mathrm{N}_{\mathrm{f}} .
$$

With a typical single slot of width .0625 in., the electric fleld between the slot surfaces would be twelve kllovolts per inch, which, in a dusty environment as found in these experiments, is sufficient to initiate arcing between the slots. The distinct advantage of a finger-type cage arises from the reduction in slot voltage and consequently, the arcing problem is negated.

\section{E. Power Loss and Resistive Loading of Cage}

The power absorbed by a conducting surface per unit area is

$$
\partial P / \partial A=|H|^{2} / 2 \sigma \delta
$$

The magnetic field $\mathrm{H}$ is approximataly

$$
H=K(R / S) N_{c} I / S,
$$


where $\mathrm{N}_{c}$ is the number of coll turns, $R$ the coll radius, $S$ the coll length, I the current, and $K(R / S)$ a geometrical factor (see Table II). Total absorbed power is then given by

$$
\mathrm{P}=\mathrm{N}_{\mathrm{c}}^{2} \mathrm{~A}_{\mathrm{c}} \mathrm{K}^{2}(\mathrm{R} / \mathrm{S}) \mathrm{I}^{2} / 2 \sigma \delta \mathrm{S}^{2},
$$

where $A_{c}$ is the area of the cage, parallel to the $Z$ - axis that lies within the volume of the coil. The serles resistance introduced by the cage is

$$
R=N^{2} A_{c} k^{2}(R / S) / \sigma \delta S^{2}
$$

For our sample concentrator-type cage and a 5-turn, 100-ampere coll,

$$
\begin{aligned}
& P=277 \text { watts } \\
& R=.0277 \text { ohm }
\end{aligned}
$$

Using elliptic integrals, we can obtain an exact expression for the magnetic fleld anywhere inside or outside the coll, in the absence of a cage. Numerically integrating the fleld over the cage area, one obtains for the power loss $P=$ 271 watts and $R=.0271$ ohms.

\section{F. Reduction in Coil Inductance}

The cage walls effectively exclude all electric and magnetic fields from the interior region, i.e., the water-cooled channels. This has the effect of reducing the field energy of the coll, which may be written

$$
\mathrm{E}_{\text {fleld }}=1 / 2 \mathrm{LI}^{2} \text {, }
$$

where $I$ is the self-inductance of the coil and I the current amplitude. If the

TABLE II

$$
\text { GEOMETRICAL FACTOR R(R/S) }
$$

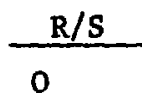

.2

.4

.6

.8

1.0

1.5

2.0

4.0

10.1

\begin{tabular}{l}
$\mathrm{K}$ \\
\hline 1.0 \\
.85 \\
.74 \\
.65 \\
.58 \\
.53 \\
.43 \\
.37 \\
.24 \\
.12
\end{tabular}
cage occupies a volume, $V_{\text {cage, Inside }}$ the coil, the field energy and the selfinductance are reduced by a factor $\left(\mathrm{V}_{\text {co11 }}\right.$ - $\left.\mathrm{V}_{\text {cage }}\right) / \mathrm{v}_{\text {co1l }}$.

This reduction in coil inductance is very important because the coll inductance is primarily responsible for the impedance of the coil-cage system. For frequencles above $10^{5}$ hertz, the coil current is well approximated by

$$
I=\Delta V_{R F} / i \omega L \text {, }
$$

where $\Delta V_{R F}$ is the potential drop across the coil. Decreasing the coil inductance increases the coil current

for a given potential drop across the coils. Because power density increases as the square of the coil current, substantially higher temperatures can be maintained in a cage that occupies a significant fraction of the coll volume. 
V. POWER SUPPLY AND COIL GEOMETRY

\section{A. Power Absorption}

The RF coil, as well as the cage, absorbs power due to the presence of alternating electric and magnetic fields at the surface. Power loss per unit area is the same as that for the cage.

$$
\partial \mathrm{P} / \partial \mathrm{a}=\mathrm{K}^{2} / 2 \sigma \delta,
$$

where $K$, the surface current, is $I / 2 \pi r_{c}$ and $r_{c}$ is the minor coil radius. Total power absorption is then

$$
P_{\text {coil }}=\frac{N_{c} I^{2} R}{2 \sigma \delta r_{c}},
$$

where $R$ is the major coil radjus. For the standard 5-turn, 100-ampere coil operated at 3 megahertz, this power is 171 watts.

B. Coil Geometry

As mentioned earlier, the Inductance of an N-turn coil of length $S$ and rauitus $R$ is

$$
L_{\operatorname{coi1} 1}=\frac{\mathrm{K}(\mathrm{R} / \mathrm{S}) \mu_{\mathrm{o}} \mathrm{N}^{2} \pi \mathrm{R}^{2}}{\mathrm{~S}} \cdot \frac{\mathrm{V}_{\operatorname{cot1}}-\mathrm{V}_{\text {cage }}}{\mathrm{V}_{\operatorname{col} 1}} .
$$

The impedence of the system is dominated by the coll inductance, hence

$$
I=\Delta V / i \omega L=\frac{S \Delta V}{\mu_{0} N^{2} \pi R^{2} \omega K(R / S)} \cdot \frac{V_{c o i l}}{\left(V_{\text {coil }}-V_{\text {cage }}\right)} .
$$

A typical magnetic field inside the coil is

$$
\begin{aligned}
& H=K(R / S) N I / S \text {, or } \\
& \left|H_{i 1}\right|=\frac{|\Delta V|}{\mu_{0} N \pi R^{2} w} \cdot \frac{V_{c o i l}}{V_{c o i l}-V_{\text {cage }}} .
\end{aligned}
$$

Thus to Increase $\mathrm{H}$ for a given power supply, one has the option of reducing the number of coil turns, $N$, decreasing the coil radius, decreasing the frequency, or building a new cage to occupy a greater volume fraction of the coil. Large magnetic fields are necessary to melt very refractory materials or those with small electrical conductivities. Substituting Eq. (5) into Eq. (1), the power input to the melt (for $\delta \gg c$ ) can be written as 


$$
P_{\text {melt }}=\frac{2 \sigma a^{4} c|\Delta V|^{2}}{1.5 \pi N^{2} R^{4}}
$$

If we make the crude assumption that the melt radius a is proportional to the coll radius $R$ (the maximum melt radius is the cage radius, which must be less than the coll radius), and the height of the melt is proportional to the coll length, then

$$
\mathrm{P}_{\text {me1t }} \approx \frac{\sigma s|\Delta V|^{2}}{\mathrm{~N}^{2}}
$$

Thermal losses from the meit are proportional to the melt surface area, hence

$$
\frac{\mathrm{P}_{\text {me1t }}}{\mathrm{P}_{\text {loss }}}=\frac{\sigma S|\Delta V|^{2}}{N^{2} R(R+S)} .
$$

If a seed melt can be established but does not densify and melt the exterior regions, it may be necessary to increase the $P_{\text {melt }} / P_{10 s s}$ ratio by increasing the coil voltage or decreasing the number of coll turns. If a seed melt cannot be established, then " $a$ " and "c" are not proportional to $R$ and $S$ and Eq. (5) suggests that the power input may be increased by (1) increasing the coil voltage $\Delta V$, (2) decreasing the number of turns $N$, or (3) decreasing the coil radius $R$.

\section{OPERATING HINTS}

During the course of these experiments several techniques were devised to efficiently initiate melts and lower the operational hazards. Some are 1 isted below.

(1) The importance of isostatically pressing the inttial charge cannot be over emphasized. The block serves as a solid base on which the seed melt can form without a large volume change destabilizing the melt. If the solid charge is sized to fit the cage snugly it also acts as a barrier to prevent.molten material from discharging between the fingers.

(2) If there is a gap between the initial charge and the cage will, it should be filled with compacted powder. Molten material invariaily destroys the quartz insulator and the ensuing arcing badly damages the equipment.

(3) A melt should be fabricated starting at the bottom by periodically adding powder. This is most easily and safely accomplished by pouring powder over the exposed skull to a 1/2-in. depth, waiting a few minutes for the powder to heat and degas, then pressing the feed through the skull with a ceramic or graphite-tipped insulating rod. One should endeavor to maintain a thin, porous skull to allow continuous outgassing during densification and feed powder melting. 
(4) The quartz finsulating sleeve should be flared at the top edge to prevent efected melt or powder from settling on the RF coils.

\section{EXPERIMENTAL RESULTS}

The purpose of these experiments was twofold: first to develop the experimental capability and second to apply the technique to real problems such as growing large single crystals of geological interes $c$ for dynamic measurements, determining the feasibility of encapsulating high-1eve1 radioactive wastes in synthetic minerals, preparing new materlals for drill bits, and producing :eproducible specimens for mechanical testing.

Experimental RF generators operating at $3.4 \mathrm{MHz}$ and $0.5 \mathrm{MHz}$ were borrowed for these experiments. Materials melted during the course of these preliminary experiments are listed in Table III.

Magnetite $\left(\mathrm{Fe}_{3} \mathrm{O}_{4}\right.$ ) and Uraninite $\left(\mathrm{UO}_{2 \pm \mathrm{x}}\right.$ ) were melted in a horizontally mounied, single-slotted, water-cooled concentrator with a $2 \times 3$ in. opening. Presumably the semiconducting properties of these materials were responsible for their absorption of $400 \mathrm{kHz}$ energy. Attempts to melt the other substances in this manner were unsuccessful.

Magnesia melted when the single-slot cage was positioned vertically and subjected to $26 \mathrm{~kW}$ at $3.2 \mathrm{MHz}$ using a 4-turn coll. A sintered MgO block, which served as the container floor, melted after twenty minutes at cemperature. The released molten oxide flowed Into a water-cooled cylinder and froze, thereby suggesting the use of a removal le plug for casting fused ceramics. The remaining materials were melted in the water-cooled finger-type cage shown in Fig. 3 .

A chromia glass was melted. The "seed" melt survived but a stable melt was not produced. Because this powder could not be isostatically pressed, the poor results can be attributed to the volume change on melting and the gases released during melting.

Early attempts to fuse thoria yielded similar results but when the frequency was reduced to $2.6 \mathrm{MHz}$ a stable melt was produced and contained for over five hours. Outgassing problems forced termination of the experiment. The product was a large fused thoria ingot weighing 1875 grams, which will require a diamond wheel in a radioactive area for cutting.

Hafnia and zirconia "seed" melts transformed easily into stable melts. Powdered hafnia was manually added to its melt until the entire cage volume (28 in.) was filled with the molten material. The ingot was cut with a diamond

TABLE III

MATERTALS MELTED

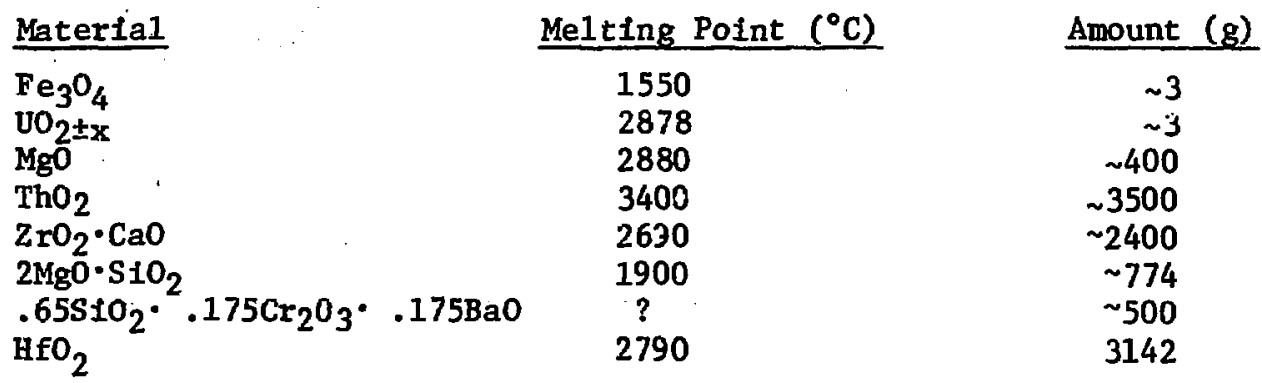


wheel, revealing a large crystalline region near the bottom and a glassy yellowish region near the top. The zirconia run yielded a large quantity of sintered and glassy zirconia, encasing a single crystalline region totalling 583 grams. The crystalline region was free from holes and microcracks, and consisted of small (mm-size) single crystals. The bulk density of the crystalIine block was $6.26 \mathrm{~g} / \mathrm{cm}^{3}$, which agrees with the Iiterature value for cubic zirconia.

Forsterite $\left(\mathrm{Mg}_{2} \mathrm{SiO}_{4}\right)$ was fused using loose powder and a graphite ring. The low melting temperature $\left(1900^{\circ} \mathrm{C}\right)$ and porous skull combination made this particular melt a comparatively easy experiment to perform.

Figure 1 shows some of the results of this investigation. The single crystal of stabilized zirconia was obtained from Wenkus through John Keem. After the Air Forse Cambridge Research Laboratory terminated their skull melting research the principle investigator acquired the RF equipment and is now marketing stabilized zirconia single crystals as synthetic diamonds.

\section{VI.II. CONCLUSIONS AND RECOMMENDATIONS}

1. The utllity of skull melting as a technique for melting kilogram quantities of refractory compounds without contamination by crucible wa.lls has been fully demonstrated. The process is safe, falrly inexpensive, and simple enough to avold high labor costs.

2. A parametric study of the physics of skull melting has been inftiated. The important variables have been identified, and their effects on the system have been calculated.

3. The power radiated by the coil as a function of frequency and coll geometry remains poorly understood. The radiated power subtracts from the power available to the melt, and may require substantial shielding to prevent interference with radio communications.

4. An instability in melt geometry due to small skin depth has been identified. To produce stable melts of a wide variety of materials, it will be necessary to obtain an RF generator with a broad frequency capability (10MHz-0.5MHz).

5. The feasibility of meiting and recrystallizing thorla in kilogram quantities has been verified. This represents the first step in developing a process to encapsulate high-level radioactive waste in non-leaching synthetic minerals.

6. Pure macroscoplc crystalline blocks of synthetic minerals free from microcracks can be fabricated in a skull melting apparatus for use in fracture mechanics studies.

\section{REFERENCES}

1. V. I. Aleksandrav, V. V. Osiko, H. M. Prokhorov, and V. M. Tatarintsev, "A New Method for Obtaining Refractory Single Crystals and Fused Ceramics," translated from Vestnik Acad. Nauk SSR 12, 29 (1973).

2. J. F. Wenkus, M. L. Cohen, A. G. Emslle, W. P. Minaski, and P. F. Strong, "Study, Design and Fabricate a Cold Cructble System," Atr Force Cambridge Research Laboratories report AFCRL-TR-75-0213 (February 1975). 
3. John Keem, Purdue University, personal communication, May 1977.

4. J. K. Hayes "Four Computer Programs Using Green's Third Formula to Numerically Solve Laplace's Equation In Inhomogeneous Media," Los Alamos Scientific Laboratory report LA-4423 (June 1970). 


\section{APPENDIX}

The 1isted results are the root mean square (RMS) values of the $B_{Z}$ and $B_{r}$ fields in the absence of the cage (theory) and with a cage present. For these calculations a five-turn coil with turns at $0,1,2,3,4$ inches was used. The coil position relative to that of the cage is measured from the cage center where $\mathrm{Z}=0$ in.

\begin{tabular}{|c|c|}
\hline $\begin{array}{l}\text { Radius } \\
\text { (cm) }\end{array}$ & ${ }^{B} z($ Tes $1 \mathrm{a})$ \\
\hline .100 & $.9725 \mathrm{E}-03$ \\
\hline .300 & $.9757 \mathrm{E}-03$ \\
\hline .500 & $.9824 E-03$ \\
\hline .700 & $.9933 E-03$ \\
\hline .900 & $.1010 \mathrm{E}-02$ \\
\hline 1.100 & $.1034 \mathrm{E}-02$ \\
\hline 1.300 & $.1069 E-U 2$ \\
\hline 1.500 & $.1124 \mathrm{E}-02$ \\
\hline 1.700 & $.1212 \mathrm{E}-02$ \\
\hline 1.900 & $.1332 \mathrm{E}-02$ \\
\hline
\end{tabular}

$\mathrm{Z}=4.75$ INCHES

\begin{tabular}{l}
$\mathrm{B} z$ (Theory) \\
\hline $.1941 \mathrm{E}-02$ \\
$.1940 \mathrm{E}-02$ \\
$.1939 \mathrm{E}-02$ \\
$.1937 \mathrm{E}-02$ \\
$.1933 \mathrm{E}-02$ \\
$.1928 \mathrm{E}-02$ \\
$.1920 \mathrm{E}-02$ \\
$.1909 \mathrm{E}-02$ \\
$.1891 \mathrm{E}-02$ \\
$.1862 \mathrm{E}-02$
\end{tabular}

\begin{tabular}{l}
${ }^{B}$ r Tes la $)$ \\
\hline $.1047 \mathrm{E}-04$ \\
$.3192 \mathrm{E}-04$ \\
$.5361 \mathrm{E}-04$ \\
$.7572 \mathrm{E}-04$ \\
$.9837 \mathrm{E}-04$ \\
$.1215 \mathrm{E}-03$ \\
$.1444 \mathrm{E}-03$ \\
$.1637 \mathrm{E}-03$ \\
$.1641 \mathrm{E}-03$ \\
$.8745 \mathrm{E}-04$
\end{tabular}

B r. (Theory) $.3640 \mathrm{E}-04$ $.1097 \mathrm{E}-03$ $.1843 \mathrm{E}-03$ $.2614 \mathrm{E}-03$ $.3420 \mathrm{E}-03$ $.4276 \mathrm{E}-03$ $.51 .98 \mathrm{E}-03$ $.6208 \mathrm{E}-03$ $.7337 \mathrm{E}-03$ $.8623 \mathrm{E}-03$

BELUX $=.915 E-05$ WEBERS

Corrected BFLUX $=.913 E-05$ WEBERS

Theoretical BFLUX $=.155 E-04$ WEBERS

$$
Z=.95 \text { INCHES }
$$

\begin{tabular}{|c|c|c|c|c|}
\hline $\begin{array}{l}\text { Radius } \\
\text { (cm) }\end{array}$ & ${ }_{z}^{B}(\operatorname{Tes} 1 \dot{a})$ & ${ }^{B}$ (Theory) & ${ }^{B} \mathrm{r}$ (Tesla) & ${ }_{-5}^{B}$ (Theory) \\
\hline .050 & $.3659 \mathrm{E}-02$ & $.2981 \mathrm{E}-02$ & $.5050 \mathrm{E}-04$ & $=.9566 \mathrm{E}-05$ \\
\hline .150 & $.3671 E-02$ & $.2982 \mathrm{E}-02$ & $.1507 \mathrm{E}-03$ & $-.2871 \mathrm{E}-04$ \\
\hline .250 & $.3696 \mathrm{E}-02$ & $.2986 \mathrm{E}-02$ & $.2546 \mathrm{E}-03$ & $-.4788 \mathrm{E}-04$ \\
\hline .350 & $.3738 \mathrm{E}-02$ & $.2991 \mathrm{E}-02$ & $.3651 \mathrm{E}-03$ & $-.6711 \mathrm{E}-04$ \\
\hline .450 & . 3802E-02 & $.2998 \mathrm{E}-02$ & $.4859 E-03$ & $-.8641 E-04$ \\
\hline .550 & . $3897 \mathrm{E}-02$ & . $3007 \mathrm{E}-02$ & $.6223 E-03$ & $-.1058 \mathrm{E}-03$ \\
\hline .650 & $.4044 \mathrm{E}-02$ & . 3018E-02 & $.7819 E-03$ & $-.1253 E-03$ \\
\hline .750 & $.4290 \mathrm{E}-02$ & $.3031 E-02$ & $.9757 \mathrm{E}-03$ & $-.1449 \mathrm{E}-03$ \\
\hline .850 & $.4769 \mathrm{E}-02$ & $.3045 \mathrm{E}-02$ & $.1205 \mathrm{E}-02$ & $-.1646 E-03$ \\
\hline .950 & $.6023 E-02$ & $.3062 E-02$ & $.1149 \mathrm{E}-02$ & $-.1844 \mathrm{E}-03$ \\
\hline
\end{tabular}

BFLUX $=.910 \mathrm{E}-05$ WEBERS

Corrected BFLUX $=.897 \mathrm{E}-05$ WEBERS

Theoretical BFLUX $=.613 \mathrm{E}-05$ WEBERS 
$\mathrm{z}=0.00$ INCHES

\begin{tabular}{|c|c|c|c|c|}
\hline $\begin{array}{l}\text { Radius } \\
(\mathrm{cm})\end{array}$ & ${ }^{B}$ (Tesla $)$ & B $z$ (Theory) & ${ }_{-\underline{r}(\operatorname{Tes} 1 a)}$ & ${ }^{B}$ (Theory) \\
\hline .050 & $.4427 \mathrm{E}-02$ & $.2473 \mathrm{E}-02$ & $.1927 \mathrm{E}-06$ & $-.1654 \mathrm{E}-04$ \\
\hline .150 & $.4433 \mathrm{E}-02$ & $.2474 \mathrm{E}-02$ & $.3840 \mathrm{E}-07$ & $-.4968 E-04$ \\
\hline .250 & $.4443 \mathrm{E}-02$ & $.2476 \mathrm{E}-02$ & $-.1156 \mathrm{E}-06$ & $-.8297 \mathrm{E}-04$ \\
\hline .350 & $.4457 \mathrm{E}-02$ & $.2479 \mathrm{E}-02$ & $-.2690 \mathrm{E}-06$ & $-.1165 \mathrm{E}-03$ \\
\hline .450 & $.4474 E-02$ & $.2484 \mathrm{E}-02$ & $-.4335 E-06$ & $-.1504 E-03$ \\
\hline .550 & $.4492 \mathrm{E}-02$ & $.2489 \mathrm{E}-02$ & $-.5951 E-06$ & $-.1848 E-03$ \\
\hline .650 & $.4509 \mathrm{E}-02$ & $.2495 E-02$ & $-.7499 E-06$ & $-.2197 \mathrm{E}-03$ \\
\hline .750 & $.4524 \mathrm{E}-02$ & $.2503 \mathrm{E}-02$ & $-.9096 \mathrm{E}-06$ & $-.2554 E-03$ \\
\hline .850 & $.4535 \mathrm{E}-02$ & $.2511 \mathrm{E}-02$ & $-.1065 \mathrm{E}-05$ & $-.2919 \mathrm{E}-03$ \\
\hline .950 & $.4541 \mathrm{E}-02$ & $.2522 \mathrm{E}-02$ & $.1065 \mathrm{E}-05$ & $-.3293 \mathrm{E}-03$ \\
\hline
\end{tabular}

BFLUX $=.913 \mathrm{E}-05$ WEBERS

Corrected BFLUX $=.905 \mathrm{E}-05$ WEBERS

Theoretical BFLUX $=.507 \mathrm{E}-05$ WEBERS

$$
\mathrm{Z}=-0.95 \text { INCHES }
$$

\begin{tabular}{|c|c|}
\hline $\begin{array}{l}\text { Radius } \\
\text { (cm) }\end{array}$ & $\mathrm{B}_{z}$ (Tesla) \\
\hline .050 & $.3657 \mathrm{E}-02$ \\
\hline, 150 & $.3669 \mathrm{E}-02$ \\
\hline .250 & $.3695 \mathrm{E}-02$ \\
\hline .350 & $.3737 E-02$ \\
\hline .450 & $.3800 \mathrm{E}-02$ \\
\hline .550 & . $3896 \mathrm{E}-02$ \\
\hline .650 & $.4043 \mathrm{E}-02$ \\
\hline .750 & $.4289 \mathrm{E}-02$ \\
\hline .850 & $.4767 \mathrm{E}-02$ \\
\hline .950 & $.6001 \mathrm{E}-02$ \\
\hline
\end{tabular}

$\mathrm{B}$ (Theory)
$.1797 \mathrm{E}-02$
$.1796 \mathrm{E}-02$
$.1795 \mathrm{E}-02$
$.1794 \mathrm{E}-02$
$.1792 \mathrm{E}-02$
$.1790 \mathrm{E}-02$
$.1787 \mathrm{E}-02$
$.1783 \mathrm{E}-02$
$.1779 \mathrm{E}-02$
$.1774 \mathrm{E}-02$

\begin{tabular}{ll}
$\mathrm{B}_{\mathrm{r} \text { (Tesla) }}$ & ${ }_{\mathrm{B}}^{\mathrm{r} \text { (Theory) }}$ \\
\hline$-.5011 \mathrm{E}-04$ & $-.1790 \mathrm{E}-04$ \\
$-.1505 \mathrm{E}-03$ & $-.5375 \mathrm{E}-04$ \\
$-.2545 \mathrm{E}-03$ & $-.8975 \mathrm{E}-04$ \\
$-.3651 \mathrm{E}-03$ & $-.1260 \mathrm{E}-03$ \\
$-.4859 \mathrm{E}-03$ & $-.1626 \mathrm{E}-03$ \\
$-.6223 \mathrm{E}-03$ & $-.1997 \mathrm{E}-03$ \\
$-.7819 \mathrm{E}-03$ & $-.2373 \mathrm{E}-03$ \\
$-.9756 \mathrm{E}-03$ & $-.2756 \mathrm{E}-03$ \\
$-.1204 \mathrm{E}-02$ & $-.3148 \mathrm{E}-03$ \\
$-.1146 \mathrm{E}-02$ & $-.3549 \mathrm{E}-03$
\end{tabular}

BFLUX $=.909 \mathrm{E}-05$ WEBERS

Corrected BFLUX $=.896 \mathrm{~F}-05$ WEBERS

Theoretica1 BFLUX $=.362 \mathrm{E}-05$ WEBERS 
$\mathrm{Z}=-4.75$ INCHES

\begin{tabular}{|c|c|c|c|c|}
\hline $\begin{array}{l}\text { Radius } \\
\text { (cm) }\end{array}$ & ${ }_{z}{ }^{3}$ (Tes $\left.1 a\right)$ & $\mathrm{B}_{2}$ (Theory) & ${ }^{\mathrm{B}} \mathrm{r}$ (Tes 1a) & ${ }^{B} r$ (Theory) \\
\hline .100 & $.9245 \mathrm{E}-03$ & $.3292 \mathrm{E}-03$ & $-.1316 \mathrm{E}-04$ & $-.6615 \mathrm{E}-05$ \\
\hline$: 300$ & $.9284 \mathrm{E}-03$ & $.3278 E-03$ & $-.3951 E-04$ & $-.1979 E-04$ \\
\hline .500 & $.9365 \mathrm{E}-03$ & $.3252 \mathrm{E}-03$ & $-.6630 \mathrm{E}-04$ & $-.3279 E-04$ \\
\hline .700 & $.9498 \mathrm{E}-03$ & . 3213E-03 & $-.9382 E-04$ & $-.4551 \mathrm{E}-04$ \\
\hline .900 & $.9700 \mathrm{E}-03$ & $.3161 \mathrm{E}-03$ & $-.1223 E-03$ & $-.5785 E-04$ \\
\hline 1.100 & $.1000 \mathrm{E}-02$ & $.3097 E-03$ & $-.1518 E-03$ & $-.6968 \mathrm{E}-04$ \\
\hline 1.300 & $.1045 \mathrm{E}-02$ & $.3022 E-03$ & $-.1812 E-03$ & $-.8093 E-04$ \\
\hline 1.500 & $.1115 \mathrm{E}-02$ & $.2937 \mathrm{E}-03$ & $-.2061 \mathrm{E}-03$ & $-.9148 E-04$ \\
\hline 1.700 & $.1227 \mathrm{E}-02$ & $.2841 \mathrm{E}-03$ & $-.2068 \mathrm{E}-03$ & $-.1013 \mathrm{E}-03$ \\
\hline 1.900 & $.1379 \mathrm{E}-02$ & $.2738 \mathrm{E}-03$ & $-.1101 \mathrm{E}-03$ & $-.1102 \mathrm{E}-03$ \\
\hline
\end{tabular}

BFLUX $=.909 \mathrm{E}-05$ WEBERS

Corrected BFLUX $=.907 \mathrm{E}-05$ WEBERS

Theoretical BFLUX $=.242 \mathrm{E}-05$ WEBERS 